\title{
MODISMOS NA ADMINISTRAÇÃO E EVOLUÇÃO DAS EMPRESAS
}

*Georges-Xavier Trépo

Qual deve ser a atitude do executivo diante dos modismos na Administração?

What is the better manager attitude in face of the stream of new management tools, turning into fashions or fads?

PALAVRAS-CHAVE:

Moda, mudança organizacional, novos modelos de adminis tração, aprendizagem organizacional.

\section{KEY WORDS:}

Fashion/fads in management tools, organizational change, new models in Administration, organization training.

*Professor Titular da HEC - École

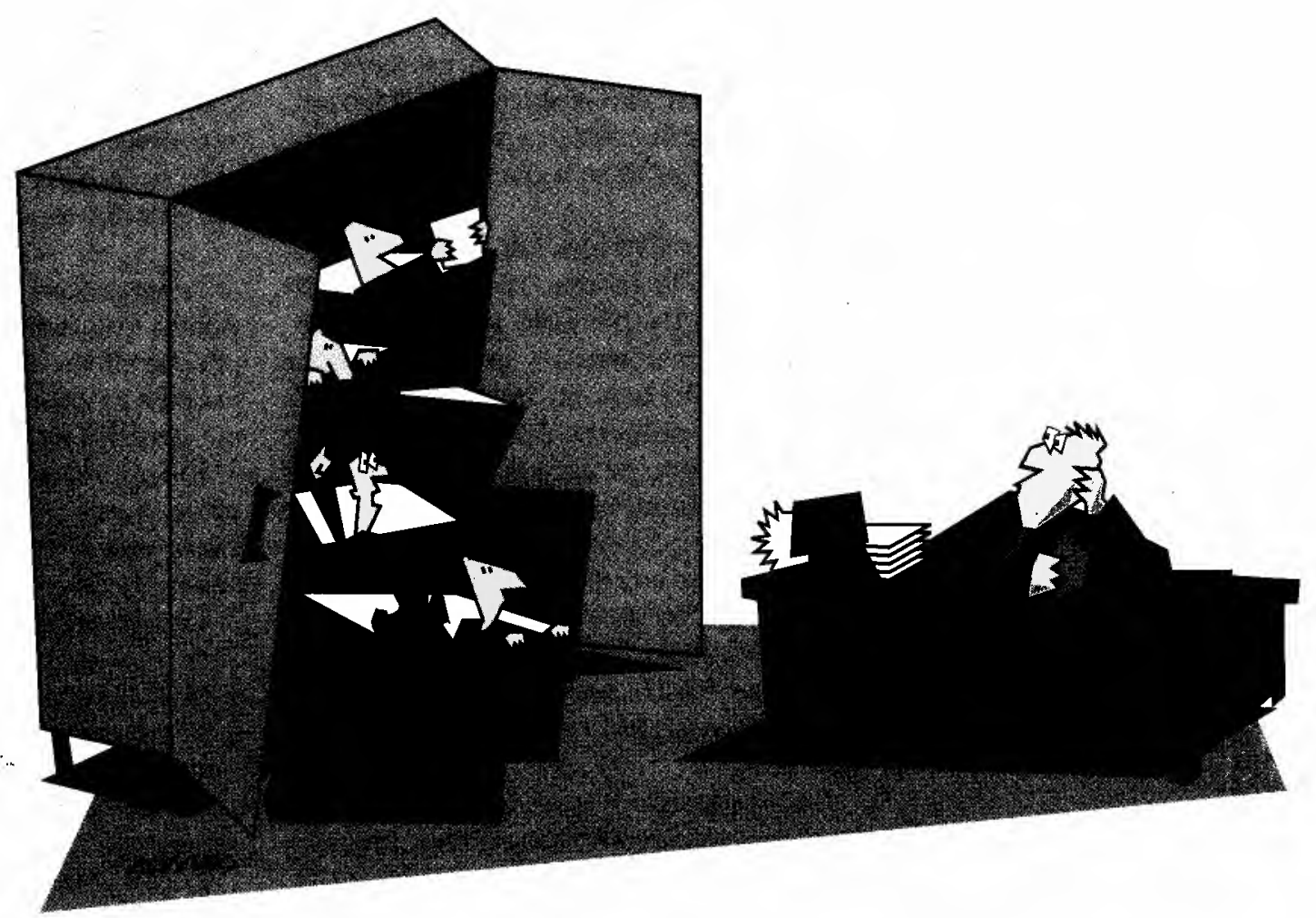


Os modismos na administração vêm e vão. Será conveniente evitá-los ou adotálos? Qual é seu verdadeiro impacto sobre as empresas a curto e médio prazo?

É chocante verificar a sucessão de novas modas na gestão empresarial desde os nos 50. Primeiro surgiu a Pesquisa Operacional (PO), depois o Controle de Gestão e a Gerência por Objetivos (GPO), nos anos 60; em seguida, o Desenvolvimento Organizacional (DO) de 1965 a 75 e o Enriquecimento de Tarefas, na década de 70 . A partir de 1980, os Círculos de Qualidade (CQ), a Qualidade Total e o Just-in-Time tomaram a dianteira. No decorrer dos anos, e sobretudo a partir de 1970 , essas novas ferramentas foram introduzidas juntamente com um modelo experimental: a pesquisa entre voluntários, os testes em regiões-piloto e, finalmente, as "tentativas" de extensão à empresa inteira.

As "tentativas" são mais ou menos enérgicas segundo as ferramentas utilizadas, sendo que os dirigentes das empresas, em alguns casos, contentam-se com o "efeito vitrine", não tendo realmente intenção de ir além disso. Uma vontade determinada de estender a "experiência" está ausente em numerosos casos (como no Enriquecimento de Tarefas, Círculos de Qualidade etc.) e presente em alguns outros (controle administrativo ou Gerência por Objetivos, apesar de muitas empresas terem renunciado a essa prática, a partir do final dos anos 60).

Estamos assistindo, assim, a um contínuo desfile de modas. Nem falemos de carrossel ou de pêndulo pois, diferentemente da "vestimenta", uma ferramenta de gestão não fica em moda senão uma única vez: a primeira. Assim, a GPO ou o enriquecimento de cargos, do qual não se fala mais atualmente, está na fase de se tornar moeda corrente, na prática.

Numerosos administradores, observando esse desfile, são bastante céticos e até mesmo cínicos: "Por que nos fixarmos na Qualidade Total? Amanhã ela estara ultrapassada. Vamos esperar o próximo gadget (bugiganga)."

Poderá parecer que, assim como os produtos, essas ferramentas têm um ciclo de vida de uma dezena de anos, num determinado país. Os diferentes países não se engajam simultaneamente a essas téc1. Midiático: através da "mídia". nesse assunto, está freqüentemente defasada em relação aos EUA (PO, GPO etc.), à Suécia (enriquecimento e grupos de trabalho) ou ao Japão (CQ, Qualidade Total, Just-in-Time). Numa empresa, o ciclo de vida "midiático" 1 da ferramenta é ainda mais curto (três a cinco anos, no máximo), verdadeiros campeões do que é efêmero (just another program).

Desde os anos 80, a analogia com a curva de vida dos produtos é ainda mais clara, pois as ferramentas de gestão são lançadas da mesma forma que o é um novo desodorante ou um refrigerante (campanhas de publicidade, vídeo etc.).

A pergunta fundamental que todos colocam é: "Para que servem essas modas e o que sobra delas?" (além da simples resposta: "Sobrará sempre alguma coisa."). Para reformular a pergunta: "Quando os Círculos de Qualidade desaparecem da mídia nacional ou interna à empresa, o que ainda restará deles realmente funcionando? Será mais ou menos que antes?"

\section{OS ENCANTAMENTOS OU AS PRÁTICAS}

Percebe-se que, para responder a essa questão, é necessário distinguir dois níveis:

- o nível da mídia (aquilo de que falam as mídias, aquilo que elas mostram);

- o nível dos comportamentos, das práticas (aquilo que é efetivamente realizado nos escritórios e oficinas).

Nossa convicção é que as modas permitem aos indivíduos e às empresas experimentar e aprender práticas novas e portanto evoluir de acordo com o esquema descrito em seguida.

Examinemos, numa empresa $X$, como se passa da campanha publicitária interna $\mathrm{CQ}$ a uma integração normalizada do $\mathrm{CQ}$ nas práticas cotidianas.

O ciclo ocorre em três fases:

- fase 1: os administradores de $X$ são bombardeados em nível nacional e internacional por mensagens sobre os méritos de uma ferramenta, os $C Q$, por exemplo. Eles acabam por sucumbir e lançam sua própria campanha interna;

- fase 2: a difusão dos CQ entre as empresas nacionais é rápida. $\mathrm{O}$ crescimen- 
to do número de círculos no país é espetacular. A sociedade $X$ lançou alguns círculos: eles se desempenharam bem, mas a sua difusão é lenta. Ao final de dois anos, torna-se mais fácil lançar outros círculos do que manter os que existem. Nesse momento, as oposições serão menos veladas e se manifestarão à luz do dia;

- fase 3: em nível nacional, ouvir-se-á falar cada vez menos desse método - começa-se a falar de casos de fracasso. As mídias estão prestes a se inclinar para um novo método "mágico". Assim, passa se dos CQ à Qualidade Total. A direção da sociedade $X$ está na iminência de projetar o lançamento de tal programa (Qualidade Total) integrando aí seus Círculos de Qualidade.

Por que esse fenômeno em três fases durou tão pouco (três a cinco anos) numa empresa? Por que essa sucessão constante de métodos (ferramentas) primeiro é conduzida em andores e depois lançada ao esquecimento? Há duas razões:

- o modo "mágico" do pensamento, onipo-
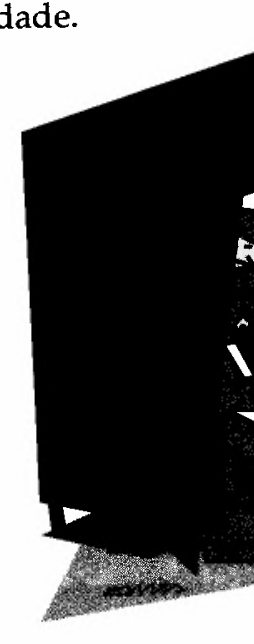

tente: os homens têm necessidade de se entusiasmar, de crer no "milagre" de se apaixonar. Os dirigentes desejam resolver quase todos os seus problemas com uma metodologia cujas "prescrições" apropriadas (no sentido médico) são bastante limitadas (não se prescrevem Círculos de Qualidade ou grupos de semi-autônomos para resolver todos os problemas!);

- as lutas pelo poder criam "campos magnéticos" que neutralizam as melhores ferramentas administrativas, ao menos a curto prazo. Em seguida, intervêm três fatores que condicionam a extensão da difusão, o que examinaremos mais adiante.

Em qual das três fases a ferramenta administrativa se difunde melhor? $\mathrm{Na}$ fase 2 ou 3? De fato, será na quarta fase, quando a ferramenta sair de moda e a mídia estiver na iminência de lançar nova moda.

Retornemos o processo em detalhe: na fase 1 , depois de a direção da sociedade $X$ ter lançado a campanha publicitária "Círculos de Qualidade", alguns crentes ou oportunistas/ambiciosos se "lançam" eles mesmos. Seus inimigos sistematicamente se colocam em posição contrária (oposição aberta ou fechada, segundo o nível hierárquico). O princípio da ação/reação rapidamente vai frear o movimento.

Quando a ferramenta sair de moda, haverá um número menor de pioneiros, mas também menos opositores e sabotadores (Michael Brimm demonstrou - e isso coincide com minha experiência que os pioneiros que obtêm sucesso nem sempre têm uma carreira brilhante, pois angariam muitos inimi$\operatorname{gos}^{2}$ ). As paixões vão se acalmar e a ferramenta poderá ser avaliada de forma mais realista e isenta.

As expectativas exageradas (quase mágicas), desmoronam e os quadros se convencem de que não se trata de um remédio miraculoso; é, ao contrário, uma ferramenta interessante, a ser usada num certo número de situações. A verdadeira difusão está prestes a começar. A ferramenta está agora integrada num repertório que os quadros podem entender e pôr em funcionamento. Desde 1982-83, há muitos cargos enriquecidos e grupos semi-autônomos trabalhando na indústria automotiva francesa, ao contrário do que ocorreu no período $1975-80$. Ou, desde 1982 , não se fala mais disso, como de 1975 a 1980 , nos tempos da grande moda.

De modo superficial e provocante, poder-se-ia propor o aforismo "Quanto mais se fala de uma ferramenta, menos ela é posta em prática e vice-versa".

\section{QUE DIFUSÃO?}

Vamos rever os três fatores que explicam a extensão da difusão.

Primeiro fator: resultados claros a curto prazo.

Esse fator, essencial para as organiza-
2. BRIMM, Michael. La diffusion des innovations en matière d'organisation. Revue Française de Gestion, mars/avril 84. 


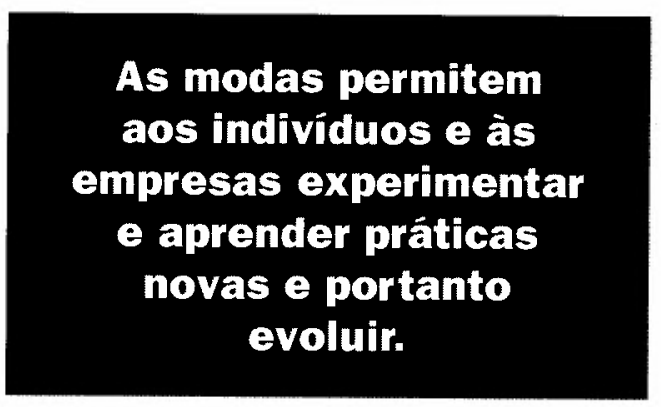

ções afrontadas pela concorrência, temperam a irracionalidade das expectativas exageradas (infantis) e a paranóia das lutas pelo poder, das quais já falamos. É difícil opor-se ao controle orçamentário ou da gestão, ou à informática, quando a vantagem competitiva é evidente. Comparar a eficácia, a curto prazo, das ferramentas (uma em relação às outras) não é escolha sensata, porque a utilidade de uma ferramenta depende de situações específicas das empresas: o que é eficaz para $X$ não será para $Y$, ou de acordo com o setor de $X$ ou $Y$, a que estas empresas pertencem.

Segundo fator: grau de contestação, por parte da ferramenta, do status quo de equilíbrio dos poderes percebidos pelos principais atores.

Os CQ são menos perturbadores que os grupos semi-autônomos para a hierarquia. Enquanto estes últimos invertem profundamente o papel da hierarquia, os primeiros não são mais que um parêntese nãotaylorista, de três a quatro horas por mês, num universo que permanece taylorista.

A Qualidade Total - QT - é muito mais perturbadora para os dirigentes que os CQ. Não será por isso que, de 1980 a 84 , quando daquelas numerosas viagens ao Japão, não se relatou nada além dos $C Q$ quando os primeiros foram sempre entendidos como um elemento e um meio (entre outros) da QT?

Terceiro fator: facilidade para comunicar e explicar a nova ferramenta.

Quando se comparam os grupos semiautônomos com $\mathrm{CQ}$, estes últimos possuem uma definição única e simples. Seus princípios de funcionamento são simples e padronizados. As regras de lançamento também. Os CQ são uma "tecnologia administrável e industrializável. Os CQ, conceito embalado, apresentam-se como um produto..."

Quando, na época do Enriquecimento

3. CHEVALIER, F., TRÉPO, Georges. Cercles de Qualité: une intégration problématique dans la gestion d'entreprise. Revue Française de Gestion, nov./déc. 1986. muitas campanhas de informação e de publicidade ricas e atraentes.

Quando se comparam os grupos semiautônomos e os CQ com relação aos três fatores, os $C Q$ vão lograr notas que facilmente fazem prever sua difusão mais rápida e mais importante. É o que se constata na fase 2 e 3 do processo da mídia e o início da fase 4, quando a ferramenta administrativa saiu da moda.

Os primeiros $C Q$ surgiram na França em 80 e 81. Em 1987, a AFCERQ - Association Française de Cercles de Qualité enumerava 15.000 deles em 1.200 empresas. Previa-se 100.000 , tendo como horizonte o ano de 1990, ou seja, à razão de cinco ou oito pessoas por círculo, 650.000 participantes dos círculos. As contagens realizadas por outra entidade, no final dos anos 70, sobre cargos enriquecidos ou em grupos, eram inferiores à metade da cifra anterior.

Em 1988, pode-se considerar que os CQ, no plano nacional, estão no final da fase 2 . Isto depende da data em que os primeiros círculos foram lançados em cada empresa. $O$ estrangulamento e o fim da fase 2 vêm após dois ou três anos para os primeiros círculos. Em muitas empresas, não há mais Círculos de Qualidade (Lesieur, HewlettPackard etc.). Em outras, não se fala mais deles (Lotus etc.): não há mais programas, estrutura e assalariados responsáveis pelos círculos, mas dentro da lógica de difusão da fase 4 , o conceito e as ferramentas são retomados, e com um apelo diferente. Desde 1983, na Renault, não se fala mais de tarefas enriquecidas e de grupos semiautônomos. Ela está passando por uma difusão, fase 4. Mas, com efeito, nas linhas de prensas automáticas de Douai, nas linhas de usinagem robotizadas do Mans, $e$ nas operações do Flins, os operadores trabalham em grupos semi-autônomos conforme a moda nos métodos japoneses. Fala-se mesmo de grupos "à la" japonesa.

\section{UMA DIFUSÃO FREADA NA PARTIDA EXATAMENTE PELOS MÉRITOS DA EXPERIMENTAÇÃO}

Embora os méritos da introdução de novas ferramentas administrativas através da experimentação sejam evidentes e sensatos, é necessário estar consciente dos freios inerentes à difusão que tal abor- 
dagem ocasiona nas fases 2 e 3, quando a ferramenta ainda se encontra em cena.

Com efeito, para que os primeiros resultados obtenham sucesso, os dirigentes da empresas:

- escolhem os setores mais "fáceis" (capacidade e motivação do chefe local);

- utilizam voluntários;

- emprestam todo seu peso para garantir o sucesso.

Essas três condições não podem ser garantidas por muito tempo, particularmente a primeira e a segunda. A terceira de forma alguma merece qualquer explicação. Para muitos dirigentes, assoberbados de todos os lados, estressados e submersos, as ferramentas "da moda" são como tábuas de salvação às quais eles se agarram com bem pouca ingenuidade $\mathrm{e}$ bastante fé. A necessidade de serem salvos e de "crer naquilo" é diretamente proporcional ao stress e à importância das dificuldades nas quais os dirigentes se debatem.

Aliás, todo dirigente esclarecido não deve "estar aberto" às novas ferramentas administrativas?

É mister, pois, ter (ou ter tido) CQ e um programa de Qualidade Total. Mas as modas, como os dirigentes, são efêmeros. Estes últimos possuem freqüentemente um horizonte de planejamento igual ou inferior àquele que eles crêem ser a duração de sua estada no cargo. Não é de se admirar que seja extremamente raro encontrar planos de cinco a dez anos para a generalização das novas ferramentas (GPO, enriquecimento e grupos na década de 70, em seguida CQ, a partir de 1981).

Com respeito a essas três ferramentas e para um horizonte de mais de 20 anos, são raras as companhias que tentaram conceber tais planos.

Finalmente, o último ponto que freia a difusão a partir das experiências-piloto é que os primeiros dirigentes que experimentaram são pioneiros. $O$ direito de errar lhes é plenamente reconhecido. Seu sucesso será narrado em alto e bom tom. Os que se seguirem são freqüentemente considerados imitadores que não têm o direito de fracassar.

Ora, isso é profundamente falso, pois não há duas situações idênticas. Os que se seguem deverão reinventar uma solução específica e local, e isso é freqüentemente mal compreendido.

\section{O QUE RESTA DEPOIS DO ALVOROÇO DA MODA? PODE-SE FALAR EM ECONOMIA?}

É necessário haver uma fase de esquecimento, de adormecimento, para que a ferramenta que mobilizou tantas esperanças excessivas (e vãs), tantas resistências envoltas em paixão, faça-se esquecer um pouco. Ela pode reaparecer disfarçada com um outro nome, evitando qualquer associação com o período precedente. Os grupos enriquecidos da Renault não mais utilizam essa denominação e não mencionam o seu vínculo anterior, pelo seguinte motivo: eles fo-

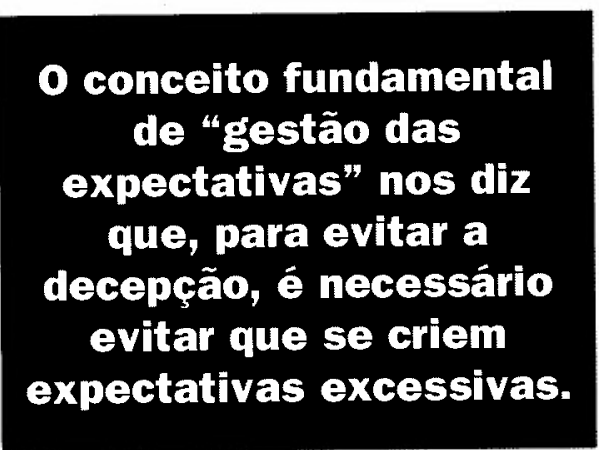
ram lançados a despeito dos métodos conhecidos e contra a hierarquia de fabricação, que se lhes opunha. Lançados novamente com uma denominação diferente, que não sofre o efeito da moda, não despertam as resistências anteriores.

O conceito fundamental de "gestão das expectativas" nos diz que, para evitar a decepção, é necessário evitar que se criem expectativas excessivas. Contudo, o excesso nas expectativas não é, por si mesmo, a fonte de energia que permite descongelar por um instante o status quo das forças presentes e modificar seu arranjo, pelo menos nos locais de experiências-piloto?

Talvez não seja possível fazer evoluir as coisas de outra maneira.

Pode-se criticar a publicidade superficial, destacando a enorme distância entre o discurso dos dirigentes e a realidade vivida por 60 a $90 \%$ dos assalariados das empresas. Pode-se mesmo falar da função ideológica do discurso como o fez $\mathrm{H}$. Landier: ${ }^{4}$ o fenômeno da moda está inscrito nas profundezas da natureza humana, permanece como a maneira principal de fazer evoluir as organizações criadas pelo homem.

$O$ dirigente, tal como o surfista sobre a onda, deve saber utilizá-las construtivamente, sem ser papalvo nem cínico, sem ser enganado nem enganar. $\square$
4. LANDIER, H. COS. Note de conjuncture sociale, 21/3/88.

Tradução de Isabella F. G. Vasconcelos, Doutoranda da EAESP/FGV e de José Luiz Celeste, Professor Assistente do Departamento de Informática e Métodos Quantitativos da EAESP/FGV. 